\title{
Investigating the Implementation of Higher Order Thinking Skills in Malaysian Classrooms: Insights from L2 Teaching Practices
}

\author{
Azian Abdul Aziz@Ahmad*, Fauziah Ismail, Noor Mala Ibrahim, Norhanim Abdul Samat
}

Language Academy, Universiti Teknologi Malaysia, 81310 UTM Johor Bahru, Johor, Malaysia

*Corresponding author: azian@utm.my

\begin{abstract}
In preparing for the $21^{\text {st }}$ century workforce, many education systems have integrated creative and critical thinking elements in the teaching and learning process by instilling higher order thinking skills (HOTS) in students. This research examines English language (L2) teachers' awareness and practices in promoting HOTS in the English Language classrooms in Malaysia. Data were collected from practicing L2 teachers through questionnaires, semi-structured interviews and structured observations. Findings of this research suggest that implementation of HOTS in the L2 classroom is very minimal and hindered by various factors, particularly those related to student, pedagogical and institutional factors. This implies the need for a more holistic and integrated approach involving L2 teachers, students and administrators in ensuring the successful implementation of HOTS in the L2 classrooms.
\end{abstract}

Keywords: Higher order thinking skills; creative thinking; critical thinking; classroom practice

C 2017 Penerbit UTM Press. All rights reserved

\subsection{INTRODUCTION}

The importance of thinking skills and abilities in Malaysian classrooms has always been emphasized, and efforts to embed teach thinking skills in the teaching and learning process have become more rigorous in response to demands in meeting the goal of Vision 2020 (Rajendran, 2001), which is to make Malaysia a fully developed country encompassing economic, political, social, spiritual, psychological and cultural dimensions (Mahathir Mohamed, 1991). This emphasis on critical thinking reflects the demands of the current information-rich society (Angeli \& Valanides, 2009) with employers putting much weight on higher order thinking skills (HOTS) (Hart Research Associates, 2010).

Thus, it is imperative that students, be equipped with HOTS. In achieving this aspiration, the most logical move to take is by preparing and equipping teachers, across the board, with the skills to teach HOTS. This move has in fact long been taken by the Ministry of Education, with teachers given exposure to the teaching of thinking skills (Rajendran, 2001; Rahil et al., 2004).

However, despite the efforts taken by the Ministry, there are indications that incorporation of HOTS in teaching is far from satisfying. A research conducted by AKEPT in 2011 as cited in the Malaysia Education Blueprint 2013-2025 (2012) revealed that only 50 per cent of 125 lessons observed in 41 schools across Malaysia engaged students in HOTS. Additionally, Malaysia's dismal ranking of 56 out of 76 countries in the 2015 PISA exercise (Malay Mail Online, 2015), which evaluated students' thinking skills in mathematics, science and reading, was an indication of students' poor problem solving ability (The Star Online, 2015)

In general, the teaching and learning of HOTS, particularly at the school level tend to be associated with subjects like science and mathematics, rather than arts subjects like language. This is perhaps why the integration of HOTS in the language classroom has been marginal (Pica, 2000). This oversight needs to be rectified, as apart from imparting linguistic knowledge to students, language classrooms are also the avenue for students to process information critically and reflect on their thinking skills (Li, 2016), and the incorporation of HOTS in the language classrooms may facilitate the production of more critical ideas at least in writing, which subsequently influences the students' use of language (Gibson, 2012). More importantly, the teaching of HOTS in language lessons could increase students' motivation to take risks (Shahini \& Riazi, 2010), monitoring and assessing of their own learning of the language (Shirkani and Fahim, 2011) and their own thinking ( $\mathrm{Li}, 2016)$. These findings clearly demonstrate the benefits of HOTS in language teaching, and thus this paper aims to investigate the practices and challenges in the implementation of HOTS in the L2 Malaysian classrooms.

\subsection{LITERATURE REVIEW}

\section{Definition of HOTS}

While educators, education administrators and policy makers have expressed agreement on the importance of HOTS and the significance of having students develop HOTS, diverging points of view on HOTS are evident (King et al., 2012). Various terms like reflective thinking, integrative thinking and deep thinking have been used to denote HOTS (Wang and Wang, 2011) depending on whose point of view HOTS are being looked at, either by psychologists, philosophers or in-practice educators. Despite varied viewpoints, there is general consensus that 
HOTS involve the integration of several higher order thinking skills that include critical, logical, reflective, metacognitive, and creative thinking (King et al., 2012; McDavitt, 1993).

Brookhart (2010) offers a more practical definition of HOTS by categorising them into three categories: (i) HOTS in terms of transfer, (ii) HOTS in terms of critical thinking, and (iii) HOTS in terms of problem solving. Transfer involves meaningful learning that requires students to understand and use what they have learned (Anderson \& Krathwohl, 2001), critical thinking includes questioning, reasoning, observing and describing, connecting and comparing and exploring viewpoints (Barahal, 2008), while problem solving requires thinking processes that lead to becoming self-regulated learners (Szabo \& Schwartz, 2011).

Despite the varied interpretation and description of HOTS, a common denominator is the involvement of a combination of intellectual processes that students have to activate in practicing HOTS. This suggests that promoting HOTS among students requires careful and extensive preparation, appropriate plans, trainings and resources and sufficient supports (among others) from various quarters of the education community, and the roles of teachers are particularly crucial.

\section{Roles of Teachers in the Implementation of HOTS}

In the classroom, teachers as the agents of change need to understand, practice and apply HOTS (Barak and Dori, 2009) in order to teach the skills effectively. More importantly, to ensure the objective of any educational programme in relation to HOTS is achieved, teachers' knowledge and beliefs are indeed the determining factors (Zohar, Degani \& Vaaknin, 2001). In the context of the Malaysian schools, teachers need to step away from the traditional emphasis on the strong development of content knowledge to the promotion of strong critical thinking and problem solving skills if HOTS are to be developed among students. In other words, the emphasis of the education system should "no longer just on the importance of knowledge, but also on the developing higher order thinking skills" (Malaysia Education Blueprint, 2012, p 25), which strongly suggests a shift in all aspects, particularly pedagogy in the classrooms (Newmann, 1991) and thus, roles of teachers.

Fogarty (2009) posits four roles of teachers in the development of students' HOTS. The first role is 'teaching for thinking' with teachers creating a classroom environment that challenges students to think. Another role is 'teaching of thinking' where teachers posing questions that require students to link their prior knowledge to novel situations. Yet another role is 'teaching with thinking', involving structuring activities that encourages students' thinking through discussions and dialogues. Finally, is 'teaching about thinking' with teachers guiding students to be more conscious of their own thinking processes.

The literature abounds with suggestions for the implementation of HOTS in the classroom. Bacon and Thayer-Bacon (1993) assert that teachers need to provide opportunities for students to be involved in 'real talk' with teachers listening to and reasoning with students, while Leaman and Flanagan (2013) propose implementing authentic spontaneous and unscripted role-playing followed by reflection-in-action which involves analysis and discussion of the role play experience. Others advocate the use of more traditional teaching approaches like problem-based learning and collaborative work (Erduran and Msimanga, 2014), and teacher scaffolding through questioning and prompting (King et al., 2012; Manzo and Manzo, 2013).

It is evident that teachers thus not only need to have a sound knowledge of what entails HOTS, but need to also play a multitude of roles in orchestrating the success implementation of HOTS in the classroom. Through the integration and infusion of the differing elements and roles, teachers may be able to engage students in activities that promote HOTS.

\section{Constraints in Implementing HOTS in the Classroom}

Despite the importance of HOTS, many teachers are ill-equipped to implement HOTS in the classroom. Although teachers display an awareness of what entails HOTS (Yeung, 2015), many are not able to transform their HOTS knowledge into practice in a sound and focused way (Zohar, 2006). Implementation of HOTS in the classroom requires teachers to transform their implicit knowledge to explicit knowledge through the language of thinking which involves not only the ability to merely name the skills, but also involve the ability to verbalize when, why, and how appropriate thinking patterns could be applied in the process of knowledge construction (Zohar, 2006).

Inadequate teacher preparation could therefore contribute to the failure of HOTS implementation in the classroom. This is because inadequate preparation tends to lead to a transmission style of teaching which hinders more challenging teacher-student interactions that promote HOTS (Raudenbush, Rowan and Cheong, 1993). It is crucial for teachers to allocate time for students' 'real talk' in developing HOTS among students as the sharing of views and articulation of reasoning would make the HOTS process more explicit (Bacon and ThayerBacon, 1993).

Another barrier to the implementation of HOTS in the classroom is teachers' emphasis on curriculum coverage. Teachers' haste in transferring knowledge for the purpose of achievement gains tends to result in students being exposed to a broad range of information and ideas, which leaves little time for activities focusing on the development of HOTS (Leming, 1998). This 'touch and go' approach contradicts the suggested explicit approach in teaching HOTS which requires the same thinking strategy to be repeated numerous times, in different contexts, and through different tasks with teachers explicitly referring to general principles of HOTS (Zohar, 2006).

In the second language (L2) classroom, challenges in the implementation of HOTS is further compounded by the stress experienced by students not fluent in the L2, resulting in classroom interaction limited to mere repetitions, cued-responses and chorus-like answers (Ngwaru, 2011). Teachers have also been found to have different expectations and perceptions of different ability students: teachers teaching students of higher academic achievement have been shown to emphasize more on HOTS than when they teach lower academic achievement students (see Zohar et al., 2001). This has led to high ability students to be given more opportunities for critical thinking and problem solving skills while low ability students given tasks requiring less cognitive skills (Donahoo, 2012) which more often than not involve only memorization and repetition.

Teachers indeed play a pivotal role in the development of students' higher thinking skills. Creating opportunities that promote HOTS through appropriate activities and teaching strategies require much effort and commitment from teachers. However, because of either real or perceived constraints, the teaching and learning processes occurring in the classroom may not be compatible with the fostering of HOTS. In the Malaysian classrooms, it is believed that the teaching and learning practices remain to be that of teacher-entered where student-teacher interactions remain minimal (Preece and Adila, 2014) and thus the lack of opportunities of activities promoting HOTS among students. Fern and Umi Kalsum (2015) argue that the implementation of HOTS in the Malaysian classrooms is relatively new and that both teachers and 
students need time to adapt. There is also a need for the teachers to be exposed to models of good teaching that emphasize on the implementation of HOTS as Ganapathy et al. (2017) claim that teachers face challenges in utilizing HOTS in their teaching. These arguments suggest there is a need to examine the current teaching and learning practices in relation to the integration of HOTS in the Malaysian classroom context. With a focus on L2 classrooms, this paper attempts to answer the following research questions:

1. What are L2 teachers' beliefs and knowledge in fostering HOTS in the L2 classrooms?

2. Do L2 teachers transfer their HOTS beliefs and knowledge in the L2 teaching and learning process?

3. What perceived factors facilitate or hinder L2 teachers' application of HOTS in their L2 teaching?

\subsection{METHODOLOGY}

The study took place in the context of teaching English as a second language (L2) in regular Malaysia public secondary schools. Regular public secondary schools encompass government-funded secondary schools not designated with any specific status like high performance schools, residential schools, premier schools, controlled schools and the like. Schools with specific designations tend to not only be selective of enrolled students, but are also more inclined to have teachers with exceptional track record as academic staff members. Thus, such schools have been excluded from this study, as these schools are not representative of the majority of secondary schools in Malaysia.

\section{Participants}

Participants in the study were 140 English language teachers, 40 males and 100 females, selected from 48 regular government-funded secondary schools in the state of Johor, Malaysia. Most participants - and consequently schools - were selected using snowball sampling method where some initial subjects were requested to identify and recruit one or more subjects to participate in the study. All participants were Bachelor degree holders, with teaching experience ranging from 3 to more than 10 years.

\section{Research Instruments}

Findings of this study were based on the triangulation of three data sources involving questionnaire, audio-recorded L2 lessons, and semistructured interview.

The questionnaire comprised 3 sections. Section A focused on participants' background information. Section B is an adaptation of Rajendran's (2001) questionnaire, containing 13 question items with an Alpha level of 0.92 in the reliability analysis test for the question items. The items were used to elicit participating teachers' beliefs and perceptions on the implementation of HOTS. Section C involved participants' self-reflection on the teaching of HOTS, and contained 11 question items with an Alpha level of 0.90 adapted from Barell (1991). Question items in Section B and C comprised Likert scale questions from a scale of 1 to 3. A three-point rather than a five-point likert scale was employed to minimize any biasness that could occur as a result of the subjective nature of the rating scale. It is believed that the dichotomy between 'agree-disagree' as well as 'often-seldom' could yield a more objective response in comparison to a rating scale of 'often-very often-seldom-very seldom' as one respondent's interpretation of 'very seldom' could be perceived as 'seldom' by another respondent. Twenty L2 lessons conducted by twenty different L2 teachers, each lasting between seventy to eighty minutes were audio-taped and transcribed. These same twenty teachers were also subjected to a semi-structured interview session with the aim of obtaining insights into their L2 teaching practice with regards to HOTS.

\section{Data Collection and Analysis}

Both qualitative and quantitative data were collected for a comprehensive analysis of the research issues. The amount of qualitative data collected is based on replication rather than sampling logic, using the 'point of saturation' principle (Richards, 2005), with data collected up to the point where the inclusion of new data does not add to the pattern that has emerged. Following the audiotaped lesson, each participating teacher was interviewed to gain further insights into his/her L2 classroom practices, particularly in relation to HOTS. The interview sessions were also audiotaped for ease of reference.

Shortly prior to the start of the audiotaped lessons, the 20 teachers were asked to complete the questionnaire. The short time gap is to prevent the teachers from deviating from the norm and displaying any irregularities in conducting their L2 lesson. The same questionnaire was also administered via email to another 120 teachers. Thus, in total, quantitative data were obtained from a total of 140 teachers. The audiotaped L2 lessons were transcribed and analysed with the aim of identifying teacher talk that promoted thinking skills in students.

Teacher talk that promotes thinking involving teacher questioning (Myhill and Dunkin, 2005) were calculated and analysed. However, only academic questions related to the content of the lesson (Good \& Brophy, 2003) were taken into consideration. The academic questions were analysed based on Moore's Mental Operation Questions (Moore, 2000), with factual and literal questions assigned as low thinking level questions, while productive and evaluative questions considered as high thinking level questions. Factual and literal questions expect answers to be drawn directly from the content of the lesson/text (Good \& Brophy, 2003) whereas productive and evaluative questions require students to integrate or analyze information to arrive at an answer (Wragg \& Brown, 2001).

Apart from teacher questioning, teacher talk in the form of a statement or imperative that contains verbs were also calculated and analysed as verbs like 'describe', 'explain', and 'tell me' have been found to promote students' thinking skills (Wilson, 2010). A list of low level and high level thinking verbs was compiled from the revised Bloom's Taxonomy (Krathwohl, 2002) and used as a basis for comparison with verbs used by the teachers. Similar to teacher questioning, only verbs related to academic content were taken into consideration, while verbs pertaining to classroom management like 'take out' and 'sit quietly' were ignored.

The twenty audiotaped interview sessions, obtained from the twenty participating teachers whose classes were observed, were 
transcribed with responses from teachers coded based on emerging themes. Data obtained from the questionnaire were analysed using SPSS statistical analysis software.

\subsection{RESULTS AND DISCUSSION}

\section{Teachers' Beliefs and Perceptions on the Implementation of HOTS}

Data generated through the questionnaire were statistically analysed to obtain a picture of how representative and widespread particular instances are, in addition to showing regularities and peculiarities of the collected data.

For teachers' beliefs and perceptions on the implementation of HOTS, the 140 participating teachers responded to statements on a Likert scale of 1 to 3, with 1 being the value for 'disagree', 2 for 'not sure' and 3 for 'agree'. Reliability of the 13 question items, measured by Cronbach's alpha, yielded a value of 0.797 , which indicates a highly acceptable internal consistency. Table 1 shows the participating teachers' beliefs and perceptions on the implementation of HOTS in the L2 classroom.

Table 1 Teacher participants' beliefs and perceptions on the implementation of HOTS

\begin{tabular}{|c|c|}
\hline & Mean \\
\hline \multicolumn{2}{|l|}{ Planning } \\
\hline 1. I'm able to use resource materials for effective learning of HOTS in the L2 Classroom & 2.79 \\
\hline 2. I know details of the curriculum for HOTS in the L2 Classroom & 2.36 \\
\hline 3. I'm able to plan a lesson to teach HOTS in the L2 Classroom & 2.32 \\
\hline $\begin{array}{l}\text { 4. I'm able to stratify the learning components to the level of students' HOTS in the L2 } \\
\text { Classroom }\end{array}$ & 2.11 \\
\hline \multicolumn{2}{|l|}{ Implementing } \\
\hline $\begin{array}{l}\text { 1. I know how to involve students actively in the teaching and learning of HOTS in the L2 } \\
\text { Classroom }\end{array}$ & 2.35 \\
\hline $\begin{array}{l}\text { 2. I know how to use different strategies and techniques to teach HOTS in the L2 } \\
\text { Classroom }\end{array}$ & 2.33 \\
\hline 3. I'm able to use different strategies and techniques to teach HOTS in the L2 Classroom & 2.28 \\
\hline 4. I know how to develop individual potential of students' HOTS in the L2 Classroom & 2.21 \\
\hline \multicolumn{2}{|l|}{ Assessing } \\
\hline $\begin{array}{l}\text { 1. I'm able to provide feedback to students for the effective learning of HOTS in the L2 } \\
\text { Classroom }\end{array}$ & 2.50 \\
\hline 2. I know how to evaluate students' HOTS improvement in the L2 Classroom & 2.36 \\
\hline \multicolumn{2}{|l|}{ Responsibility } \\
\hline $\begin{array}{l}\text { 1. A good teacher should adapt the curriculum to the needs of students' HOTS even if this } \\
\text { involves adding more work }\end{array}$ & 2.93 \\
\hline $\begin{array}{l}\text { 2. It is the duty of the teacher to know more on their own for the teaching of HOTS in the } \\
\text { L2 Classroom }\end{array}$ & 2.79 \\
\hline $\begin{array}{l}\text { 3. To be a better teacher one needs continuous training in the teaching of HOTS in the L2 } \\
\text { Classroom }\end{array}$ & 2.79 \\
\hline
\end{tabular}

Amongst the four components pertaining to planning, implementation, assessment, and responsibility, participating teachers showed a high awareness of teacher responsibility in the implementation of HOTS with the mean value of all three statements skewed more towards 3, indicating their agreement with the statements. Despite this awareness, when it comes to planning, implementing, and assessing, apart from the ability to use resource materials for effective learning of HOTS in the L2 classroom which showed a mean of 2.79, all the other statements showed a mean value of 2.5 or less which is skewed towards the value of 2 , indicating the teachers were unsure of their plans, implementation and assessment of HOTS in the classrooms.

For teachers' self-reflection on the teaching of HOTS, participating teachers also responded on a Likert scale of 1 to 3 , with 1 being the value for 'seldom', 2 for 'sometimes' and 3 for 'often'. Likewise, reliability of the 11 question items was measured by Cronbach's alpha. The Cronbach's alpha value was 0.511 which indicates a moderately acceptable internal consistency. Table 2 shows the participating teachers' self-reflection on the teaching of HOTS in the L2 classroom. 
Table 2 Teacher participants' self-reflection on the teaching of HOTS

\begin{tabular}{|c|c|}
\hline & Mean \\
\hline \multicolumn{2}{|l|}{ Scaffolding } \\
\hline 1. I encourage students to seek alternative answers & 2.64 \\
\hline 2. Most questions I posed during class can he answered with short or one-word answers & 2.45 \\
\hline $\begin{array}{l}\text { 3. When students pose unusual or divergent questions, } \\
\text { I ask, "What made you think of that?" }\end{array}$ & 2.36 \\
\hline 4. I encourage students to give reasons for making statements & 2.33 \\
\hline 5. I stress what to think, not how to think & 2.07 \\
\hline $\begin{array}{l}\text { 6. When a decision has to be made between involving the class in a discussion of an } \\
\text { intriguing student idea (topic related) or moving on to "cover" content, I choose the } \\
\text { latter }\end{array}$ & 1.98 \\
\hline 7. I encourage students to generate their own questions, which we then seriously consider & 1.78 \\
\hline \multicolumn{2}{|l|}{ Students' Participation } \\
\hline 1. Students relate topics in lesson to experiences in other subjects or in their personal lives & 2.23 \\
\hline 2. Students actively listen to each other & 1.99 \\
\hline 3. Students spend time working collaboratively to solve questions posed & 1.97 \\
\hline 4. Students spontaneously engage in critiquing each other's thinking & 1.93 \\
\hline
\end{tabular}

In reflecting on their HOTS teaching practice, the participating teachers indicated 'sometimes' as their primary option. The only statement which generated a mean value skewed towards the value of 3 which indicates 'often' is pertaining to encouraging students to seek alternative answers with a mean value of 2.64. The mean value for the other statements was all less than 2.5, indicating that the HOTS teaching practices are only implemented 'sometimes'. The lowest mean value was for 'I encourage students to generate their own questions, which we then seriously consider' with a value of 1.78 which suggests that this practice is either 'sometimes' or 'seldom' implemented in the classroom.

Table 3 Correlation between teacher participants' belief and perception, and self-reflection

\begin{tabular}{lccc}
\hline & N & r & p \\
\hline Teachers' Belief and Perception and Self-Reflection & 140 & -0.097 & 0.274 \\
\hline
\end{tabular}

The correlation is when p-value is smaller than 0.05. Thus, since the p-value as shown in Table 3 is 0.274 , it can be concluded that there is no significant correlation between participating teachers' beliefs and perceptions on the implementation of HOTS and the teachers' selfreflection on the teaching of HOTS. This suggests that teachers' beliefs do not influence their HOTS teaching practice in the L2 classroom.

\section{Teachers' HOTS Practice}

Twenty English language (L2) lessons conducted by twenty L2 teachers, each lasting between seventy and eighty minutes were audiotaped and transcribed. In total, data were obtained from 1,550 minutes of L2 lessons. In discerning the implementation of HOTS in the L2 classroom, teacher questioning and use of verbs were analysed.

\section{Teachers' Use of Questions}

Teacher questioning is aimed at enhancing students' understanding, arousing their curiosity and engaging them to be active and thinking learners. This suggests that effective teacher questioning can foster students' HOTS. Table 4 below shows the category and number of questions generated by the twenty L2 teachers.

Table 4 Category and frequency of teacher participants' questions

Total number of academic questions: 928

\begin{tabular}{cc}
\hline Total number of academic questions: $\mathbf{9 2 8}$ \\
\hline Low level questions & High level questions \\
$\mathbf{8 8 8}(\mathbf{9 6 \%})$ & $40(4 \%)$ \\
\hline
\end{tabular}


Table 4 shows that participating teachers' use of questions in the classrooms. Questions posed that required students to provide surface level information, factual or literal answers were considered as low level questions, while questions that required students to analyse, infer, synthesise and evaluate information which were essential to trigger students' critical thinking process were considered high level. Based on the table it is obvious that the participating teachers mostly asked low level questions in the L2 classroom with $96 \%$ of the questions asked fell into this category and only $4 \%$ of the questions could be categorised as high level questions.

\section{Teachers' Use of Verbs}

Teachers could foster students' thinking process upon the use of specific verbs that could trigger students' thinking process (Astington and Olson, 1990). Astington and Olson refer to these verbs as 'the language of the mind' and include verbs like explain, argue, predict, and suggest, most of which appear in Bloom's taxonomy (Krathwohl, 2002). As mentioned in the methodology section, only those verbs pertaining to academic content were taken into consideration. The list of verbs generated by the twenty teachers in their L2 lessons, sequenced in order of frequency, is shown in Table 5.

Table 5 List and frequency of teacher participants' use of 'thinking verbs'

\begin{tabular}{|c|c|c|c|}
\hline Verb & Low level & High level & Ambiguous \\
\hline read & & & 1 \\
\hline look at & I & & 1 \\
\hline try & & I & \\
\hline guess & & I & \\
\hline give & I & & \\
\hline tell & I & & \\
\hline recite & I & & \\
\hline choose & l & & \\
\hline think & & I & \\
\hline give & & I & \\
\hline discuss & & & I \\
\hline know & l & & \\
\hline answer & & & I \\
\hline find & I & & \\
\hline spell & I & & \\
\hline identify & I & & \\
\hline match & I & & \\
\hline construct & & I & \\
\hline listen & l & & \\
\hline Total & $11(55 \%)$ & $5(25 \%)$ & $4(20 \%)$ \\
\hline
\end{tabular}

Table 5 shows the most commonly used verbs used in the twenty observed L2 lessons that triggered students' thinking process. The evidence suggests that most of the verbs used by the L2 participating teachers (55\%) triggered low level thinking skills that generated merely factual and literal answers from students, while only $25 \%$ of the verbs used were able to generate HOTS among students. It was also found that the use of four verbs, namely, read, write, discuss and answer, was ambiguous as the use of these four verbs lacks the ability to direct students' attention to the thinking process. Rather, the four verbs tend to act as an imperative that requires students to take action. Typical use of these verbs includes: 'Read the text'; 'Write the sentences'; 'Discuss in your groups'; 'Answer the comprehension questions'.

\section{Factors Influencing Application of HOTS in L2 Teaching}

Based on the interview data, three factors, namely, student, pedagogical and institutional factors emerged as influencing teachers' pedagogical decision in the implementation of HOTS in the L2 classroom.

\section{Student Factors}

Teachers view teaching L2 to most students in regular public secondary schools in Malaysia to be an uphill task in itself because most students have yet to reach the basic L2 proficiency level. Thus, most teachers were wary of including any additional HOTS elements in the L2 teaching and learning process. Typical comments from teachers with regards to the link between students' proficiency and the inclusion of HOTS in their teaching include:

T7 : Low ability and even moderate ability students are ill equipped to answer any HOTS questions. They don't have the language to articulate their thoughts, so what is the purpose of HOTS in the L2 classroom?

T11: Students in my class are still struggling with basic grammar and this is a heavy load for them. I see no reason why we should burden them more with HOTS.

Thus, it is obvious that the teachers' pessimistic stance is based on the assumption that since students have yet to master the L2, the 
students do not have the language to participate in any HOTS endeavor.

Pedagogical Factors

Insights gained via the interview sessions support the findings of the questionnaire. Despite acknowledging the significant role teachers play in the implementation of HOTS in the L2 classroom, most teachers indicated they were hesitant in implementing HOTS as they lack the skill to plan, implement and assess HOTS in an L2 classroom, especially with students of varying proficiency levels. As one teacher succinctly articulated:

T3: If I were to ask a HOTS question, only the same student will answer. She can answer or try to answer as she has the language. The rest of the class will keep quiet. I'm not sure how to involve the whole class in HOTS. So, I seldom implement HOTS as it does not benefit the whole class.

\section{Institutional Factors}

It was found that time management and large classroom size influenced the pedagogical decisions of L2 teachers in the implementation of HOTS, as reflected in the comment below:

T20: There are too many pupils in my classroom, 38 of them. I cannot facilitate them one to one as there are just too many.

Consequently, teachers were of the opinion that including HOTS in the teaching and learning process is time consuming, resulting in them unable to cover the English language syllabus. The extract below is a typical response from the L2 teachers:

T6: Encouraging students to think from different perspectives is very time consuming. Due to time constraints we usually don't have time to explore other possible answers.

Discussion

Thinking is inherent in the teaching and learning process, and teachers' acknowledging their responsibility in enhancing learners' thinking skills, including higher order thinking skills is very crucial. Nevertheless, simply acknowledging this responsibility and having the ability to use resource materials in teaching HOTS could not guarantee that HOTS are actually being practiced in the L2 classrooms.

The findings of this study reveal that L2 teachers were aware of their responsibility to include HOTS in their teaching and believed that they could use resources for the effective learning of HOTS in their classrooms. However, the findings also disclose that the L2 teachers were not able to capitalise their roles and potential in implementing HOTS in the classrooms as most of them were uncertain on how to plan, implement and assess HOTS in the classrooms, for example in terms of developing individual student's potential with HOTS and evaluating students' HOTS improvement. In fact, based on their self-reflection on HOTS teaching practices, it is evident that the L2 teachers did not routinely emphasize on HOTS during lessons. Teachers' preference not to focus on promotion of HOTS in the classrooms is not surprising. For example, based on their interviews and observations of five English for Specific Purposes (ESP) lecturers in one public university in Malaysia, Dwee et al. (2016) found out that the lecturers preferred to focus on the subject matter and not teaching practices that promote critical thinking, despite having awareness that their students lack critical thinking skills. Interestingly, Li (2016) also identified similar findings among EFL teachers in China.

The analysis of the L2 teachers' recorded lessons demonstrates further the L2 teachers' struggle to capitalise on instructional language that can encourage learners' HOTS. Teachers' frequent use of low level questioning and low level thinking verbs in the L2 classroom indicates that instructional language is being underutilised in promoting learners' HOTS. In other words, teachers have not utilised the instructional language to deliberately foster students' higher order thinking abilities. Students' not having much exposure to high-level questioning is also proven by other researchers. Habsah (2006) discovered that students have been exposed more frequently on "what to learn" than on "how to learn". Dwee et al. (2016) also found out that language instructors focused so much on questions that focus on "what", "how many" and "where" which required factual answers. Similarly, the high occurrence of low level questions as found in this study resonates the findings in Sidhu, Chan and Kaur's (2010) study of five primary school teachers dealing with Contemporary Children's Literature programme. Their data revealed that questions that promote HOTS accounted only for 10\% of all questions asked, as teachers preferred to focus on students' comprehension on subject matter.

Teachers' lack of emphasis on HOTS as emerged in this study should not be conveniently ignored. As expressed by the participating teachers, there were various contributing factors affecting their ability to implement HOTS in their classrooms, particularly the students and institutional factors that predominantly influence pedagogical decisions of the teachers. While teachers' knowledge and beliefs and perhaps strategies on implementation of HOTS in L2 classrooms could be enhanced - for example through trainings - issues related to large class size, time constraint and its effect on syllabus to be covered as well as low students' L2 proficiency levels and students of varied proficiency levels being put in one classroom require careful and thorough considerations from the educational authority. These issues are even more significantly crucial when the development of HOTS among students should target at all students, regardless of their backgrounds. And, based on some previous studies mentioned above, it is obvious that the lack of emphasis on HOTS in classrooms is common across educational levels (primary and secondary schools and tertiary) in Malaysian education system, suggesting that there is a pressing need for the issue to be urgently addressed. 


\subsection{CONCLUSION}

The inclusion of HOTS in the L2 classroom demands proper and careful planning, particularly at the implementation stage. While it could be relatively manageable for L2 teachers to step away from the traditional classroom focal point i.e. the importance of knowledge, the inclusion and application of HOTS in classrooms may not. On the part of the teachers, they must be equipped with the right knowledge and skills to effectively explain and model HOTS strategies and at the same time are willing to provide students with ample opportunities to activate and utilise HOTS in the L2 classrooms. Students, on the other hand, should be ready to be challenged to become active learners that monitor and reflect on their own learning processes while evaluating and interpreting information in critical manner. Indeed the implementation of HOTS has its own challenges, but with the right integrated efforts from various quarters, valued outcomes may prevail.

\section{Acknowledgements}

The authors gratefully acknowledge financial support from the Ministry of Higher Education, Malaysia through its Fundamental Research Grant Scheme (FRGS) (Ref: FRGS/1/2014/SS109/UTM/02/09). Appreciation also goes to the UTM Research Management Centre for its technical support.

\section{References}

Anderson, L. W. and D. Krathwohl (eds.) (2001). A Taxonomy for Learning, Teaching and Assessing a Revision of Bloom's Educational Objectives. New York: Longman.

Angeli, C. and Valanides, N. (2009). Instructional effects on critical thinking: Performance on ill-defined issues. Learning and Instruction. 19, 322-334.

Astington, J. W., \& Olson, D. R. (1990). Metacognitive and Metalinguistic Language: Learning To Talk About Thought. Applied Psychology: An International Review. $39,77-87$.

Bacon, C.S. and Thayer-Bacon B. J. (1993). "Real Talk": Enhancing Critical Thinking Skills through Conversation in the Classroom. The Clearing House. 66 (3), 181184.

Barahal, S. (2008) Thinking about Thinking: Preservice Teachers Strengthen their Thinking Artfully. Phi Delta Kappan 90 (4). $298-302$.

Barak, M. and Dori, Y.J. (2009). Enhancing Higher Order Skills Among Inservice Science Teachers Via Embedded Assessment. Journal Science Teacher Education. 20, 459-474.

Barell, J. (1991) Self-reflection on your teaching: A checklist. In Costa, A. L. (Ed), Developing Minds: A Resource Book for Teaching Thinking. Revised Edition, Volume 1. United Sttaes of America. ASCD.

Brookhart, S.M. (2010). How to Assess Higher-Order Thinking Skills in Your Classroom. Virginia USA. ASCD Alexandria.

Donahoo, S. (2012). Should all forms of ability grouping be eliminated in Schools? In Brown, F., Hunter, R.C., and Donahoo, S. (Eds). Diversity in Schools. Thousand Oaks. Sage.

Dwee, C. Y., Anthony, E. M., Salleh, B. M., Kamarulzaman, R., \& Kadir, Z. A. (2016). Creating Thinking Classrooms: Perceptions and Teaching Practices of ESP Practitioners. Procedia-Social and Behavioral Sciences, 232, 631-639.

Erduran S. and Msimanga A., (2014), Science Curriculum Reform In South Africa: Lessons For Professional Development From Research On Argumentation In Science Education. Education as Change. 18(1). 33-46.

Fern, C. C. S., and Umi Kalsum, M. S. (2015). The emphasis of Higher Order Thinking (HOT) in the curriculum and the implementation in reality. In Knowledge, Service, Tourism \& Hospitality: Proceedings of the Annual International Conference on Management and Technology in Knowledge, Service, Tourism \& Hospitality 2015 (SERVE 2015), Bandung, Indonesia, 1-2 August 2015 (p. 61). CRC Press.

Fogarty, R. (2009). Brain-compatible Classrooms (3rd ed.). Thousand Oaks, CA: Corwin.

Ganapathy, M., Singh, M. K. M., Kaur, S., \& Kit, L. W. (2017). Promoting Higher Order Thinking Skills via Teaching Practices. 3L: Language, Linguistics, Literature, 23(1)

Gibson, M. (2012). Integrating Higher-Order Thinking Skills Into The L2 Classroom. [Online]. Available from: http://dadun.unav.edu/bitstream/10171/27571/1/Gibson.pdf (accessed 28.06.17)

Good, T. L. and Brophy, J. E. (2003). Looking in Classrooms (9th ed.). Boston: Pearson.

Habsah, H. (2006). Dimensions of Questioning: A Qualitative Study Of Current Classroom Practices in Malaysia. TESL-EJ, 10 (2).

Hart Research Associates. (2010). Raising The Bar: Employers' Views On College Learning In The Wake Of The Economic Downturn. Washington, DC: Hart Research Associates.

http://www.themalaymailonline.com/malaysia/article/as-singapore-tops-world-malaysia-ranks-low-on-latest-oecd-maths-and-science

King, F.J., Goodson, L. and Rohani, F. (2012). Higher Order Thinking Skills: Definitions, Teaching Strategies, Assessment. http://www.cala.fsu.edu/files/higher_order_thinking_skills.pdf. Retrieved on 26February 2014.

Krathwohl, D. R. (2002).A revision of Bloom's Taxonomy: An Overview. Theory Into Practice, 41(4), 212-218.

Leaman, L., and T. Flanagan. 2013. Authentic Role-Playing as Situated Learning: Reframing Teacher Education Methodology for Higher-Order Thinking. Studying Teacher Education. 9 (1). 45-61.

Leming, J.S. (1998). Some Critical Thoughts about the Teaching of Critical Thinking. The Social Studies, 89(2), 61-66.

Li, L. (2016). Integrating Thinking Skills In Foreign Language Learning: What Can We Learn From Teachers' Perspectives?. Thinking Skills and Creativity, 22, 273288.

Mahathir Mohamed (1991). Malaysia: The Way Forward. Kuala Lumpur, Malaysia: Center for Economic Research \& Services, Malaysia Business Council.

Malay Mail Online (2015). As Singapore Tops World, Malaysia Ranks Low On Latest OECD Maths And Science Scores. Retrieved on 16 March 2016 from

Malaysia Education Blueprint 2013-2025. (2012). Preliminary Report, September 2012. Malaysia Ministry of Education.

Manzo, U. and Manzo, A.V. (2013) The Informal Reading-Thinking Inventory:

McDavitt, D. S. (1993). Teaching for Understanding: Attaining Higher Order Learning And Increased Achievement Through Experiential Instruction. (ERIC Document Reproduction Service No. ED 374 093))

Moore, K. D. (2000). Classroom teaching skills (3rd ed.). New York: McGraw-Hill Inc.

Myhill, D. and Dunkin, F. (2005). Questioning Learning. Language and Education, 19(5), 415-427.

Newmann, F. M. (1991). Higher order Thinking In The Teaching Of Social Studies: Connections Between Theory And Practice. In J. Voss, D. Perkins And J. Segal (Eds.) Informal Reasoning And Education, 381-400.

Ngwaru, J.M. (2011) Alternative Perspectives to English Teaching in Bilingual Contexts: A Case for Zimbabwe. Lambert Academic Publishing.

Pica, T. (2000). Tradition And Transition In English Language Teaching Methodology. System, 29, 1-18.

Preece, A. S. and Adila, J. 2014). Philosophical Inquiry in the Malaysian Educational System-Reality or Fantasy? Analytic Teaching And Philosophical Praxis, 35 (1), $26-38$. 
Rahil, M., Zaidatol Akmaliah, L.P., Habibah, E. and Mohd Majid, K. (2004). The Incorporation of Thinking Skills in the School Curriculum. Kajian Malaysia. 12(2), 23-33.

Rajendran, N. (2001). The Teaching of Higher-Order Thinking Skills in Malaysia Journal of Southeast Asian Education; 2(1); $42-65$

Raudenbush, S.W., Rowan, B., and Cheong, Y. F. (1993) Higher Order Instructional Goals in Secondary Schools: Class, Teacher, and School Influences. American Educational Research Journal; 30(3), 523-553

Richards, L. (2005). Handling Qualitative Data. A practical Guide. London: Sage Publications Ltd.

Shahini, G., and Riazi, A. M. (2010). A PBLT Approach To Teaching ESL Speaking, Writing, And Thinking Skills. ELT Journal, 65(2), 170-179.

Shirkhani, S.and Fahim, M. (2011). Enhancing Critical Thinking in Foreign Language Learners. Paper presented in 1st International Conference on Foreign Language Teaching and Applied Linguistics, May 5-7, 2011. Sarajevo.

Sidhu, Gurnam Kaur, Yuen Fook Chan, and Sarjit Kaur. "Instructional Practices In Teaching Literature: Observations Of ESL Classrooms in Malaysia." English Language Teaching; 3.2 (2010), 54.

Szabo, Z. \& Schwartz, J. (2011). Learning Methods For Teacher Education: The Use Of Online Discussion To Improve Critical Thinking. Technology, Pedagofy and Education, 20(1). 79-94.

The Star Online (2015) Doing better in Pisa. Retrieved on 16 March 2016 from http://www.thestar.com.my/news/education/2015/06/28/doing-better-in-pisa/

Twenty-First-Century Assessment Formats for Discovering Reading and Writing Needs - and Strengths. Reading \& Writing Quarterly: Overcoming Learning Difficulties. 29(3). 231-251

Wang, S. and Wang, H. (2011).Teaching Higher Order Thinking In The Introductory MIS course: A Model-Directed Approach. Journal of Education For Business, 86, 208-213

Wilson, J.M. (2010) Using Words About Thinking: Content Analyses Of Chemistry Teachers' Classroom Talk, International Journal of Science Education, 21(10), $1067-1084$

Wragg, E. C., \& Brown, G. (2001). Questioning In The Secondary School. London: Routledge Falmer.

Yeung, S.S. (2015). Conception Of Teaching Higher Order Thinking: Perspectives of Chinese Teachersin Hong Kong. The Curriculum Journal, 26 (4), 553-578,

Zohar, A. (2006). The Nature and Development of Teachers' Metastrategic Knowledge in the Context of Teaching Higher Order Thinking. The Journal of the Learning Sciences, 15 (3), 331-377.

Zohar, A., Degani, A., \& Vaaknin, E. (2001). Teachers' Beliefs About Low-Achieving Students And Higher Order Thinking. Teaching and Teacher Education, 17(4), 469-485. 